\title{
The Road to Recovery \#3: Facilitating Community Resilience for Effective Pandemic Response ${ }^{1}$
}

\author{
Cody Gusto, Colby Silvert, and John Diaz ${ }^{2}$
}

This third publication in the Road to Recovery series provides information and recommendations to support Extension professionals' ability to facilitate capacity building and resilience development for communities during COVID-19 and potential future pandemic situations.

\section{Introduction}

While cooperative Extension has long engaged in disaster preparation, emergency response, and postdisaster recovery efforts across contexts, the coronavirus disease 2019 (COVID-19) pandemic has presented unique challenges for Extension professionals to adequately address the health, safety, and well-being of both rural and urban client communities (Fawcett et al., 2020; University of Wisconsin, 2020). In addition to the medical risks posed by transmitting and contracting the virus, the outbreak has exacerbated preexisting vulnerabilities within communities, further destabilizing the financial security of certain clientele and stakeholder groups. According to Béné (2020) and Devereux et al. (2020), localized lockdowns and mobility restrictions have contributed to a sharp, global decline in family incomes with devastating downstream effects on community food security and the resilience of local food systems. Researchers are only now beginning to account for the scale of disruption and adverse impact on global food production, availability, quality, and price stability (Béné, 2020).
COVID-19 has not only introduced community-scale disruptions and stressors, it has impacted response and recovery efforts (Fawcett et al., 2020). There is prevailing consensus among Extension professionals familiar with the disruption and devastation wrought by disasters (both natural and "man-made") that building resilience, capacity, and social capital within an affected community is the most effective strategy to mitigate postdisaster impact and prepare for future disasters (Lindsey et al., 2018; Ali et al., 2020). Previous approaches promoted resilience by identifying community members' crisis-time needs and ideas through town hall meetings and participatory assemblies. However, these large, in-person, group-based activities are not feasible during the current pandemic situation without significant adaptation (Fawcett et al., 2020).

Building on the second publication in this series, which aimed to promote physical and emotional trust during field and virtual engagement with clientele, this publication provides recommendations for effective community-scale engagement and organizing. Considering unprecedented challenges posed by COVID-19, we focus on alternative strategies for facilitating resilience, capacity, and social capital for community stakeholders and clients. Past approaches to promote resilience, capacity, and social capital for disaster preparedness and recovery are addressed briefly below, followed by adapted recommendations for the current COVID-19 context and future pandemic scenarios.

1. This document is AEC717, one of a series of the Department of Agricultural Education and Communication, UF/IFAS Extension. Original publication date January 2021. Visit the EDIS website at https://edis.ifas.ufl.edu for the currently supported version of this publication.

2. Cody Gusto, graduate student; Colby Silvert, graduate assistant; and John Diaz, assistant professor and Extension specialist, Department of Agricultural Education and Communication; UF/IFAS Extension, Gainesville, FL 32611.

The Institute of Food and Agricultural Sciences (IFAS) is an Equal Opportunity Institution authorized to provide research, educational information and other services

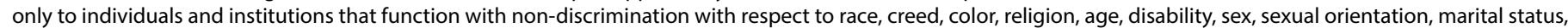

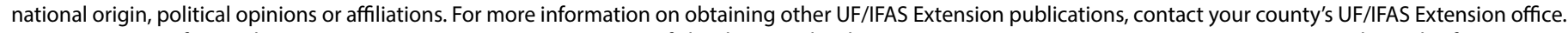
U.S. Department of Agriculture, UF/IFAS Extension Service, University of Florida, IFAS, Florida A \& M University Cooperative Extension Program, and Boards of County Commissioners Cooperating. Nick T. Place, dean for UF/IFAS Extension. 


\section{Extension in Disaster Recovery Contexts}

From the development and distribution of educational resources to the structured facilitation of a disaster recovery planning process, Extension personnel provide critical services and support for community stakeholders during disaster and postdisaster periods (Eighmy et al., 2012; Lindsey et al., 2018; Ali et al., 2020; Fawcett et al., 2020). One of the most impactful services Extension professionals can provide, however, is the development of targeted strategies to promote and enhance a community's resilience and capacity by leveraging its existing social capital (Lindsey et al., 2018). Important concepts related to community resilience and capacity building are defined below.

Resilience: The ability of a community to adapt and return to a state of equilibrium (socially, economically, environmentally, institutionally, or infrastructurally) in response to a destabilizing disaster event (Kim \& Marcouiller, 2016).

Capacity Building: The process by which stakeholders acquire, expand, and retain the skills, knowledge, tools, equipment, and other resources needed to improve the quality of life in their own community. May be measured by the level of motivation to carry out certain initiatives, the presence and strength of interorganizational collaborations or social networks, robust and active communication networks, and much more (Mitrofanova, 2004).

Social Capital: The social norms, values and networks that encourage trust, collaboration, reciprocity, and action in a community (Aldrich \& Meyer, 2014; Lindsey et al., 2018).

Jointly, these concepts can be leveraged to understand and address the health of a community in disaster scenarios. Previous efforts to link community resilience, capacity building, and social capital to effective disaster response have situated the concepts as a joint process and outcome to enhance the "....will or ability of residents to undertake collective action and/or in locally desired improvements to community quality of life" (Weaver, 2016, p. 1). Generally, communities that have greater capacity and social capital (e.g., strong social support networks, community cohesion) are "...more likely to have the resources needed to minimize loss due to the disaster," making them more resilient (Lindsey et al., 2018).

These concepts and approaches are also familiar to UF/ IFAS personnel who have been deeply involved in disaster preparation and recovery efforts in Florida. The UF-led Healthy Gulf, Healthy Communities (HGHC) program, which was tasked with monitoring and assisting coastal communities in their recovery from the Deepwater Horizon (DWH) oil spill, is a prime example of this resilience and capacity-building engagement (Monaghan et al., 2018). While we have learned a great deal about applying these concepts in previous crises, there are unique challenges associated with COVID-19 and recovery. These barriers are addressed briefly below, followed by recommendations for current and future Extension engagement.

\section{Barriers to Building Community Resilience during COVID-19}

- One of the first challenges Extension professionals may encounter in facilitating community-level resilience during COVID-19 is understanding the nature of this crisis, which impacts how best to find and connect resources and support with communities. An instinct may be to categorize COVID-19 as a "disaster" requiring mobilized engagement similar to "conventional" disaster scenarios (e.g., hurricanes, flooding). In this respect, the Federal Emergency Management Agency (FEMA) has in fact indicated that COVID-19 appropriately qualifies as a natural disaster. The White House, in March of 2020, also approved emergency disaster assistance declarations (FEMA, n.d.) in all 50 states, the District of Columbia, four US territories, and dozens of tribal agencies (FEMA, n.d.).

- Given the continued observance of social distancing guidelines, communication opportunities may be restricted in various ways. The increased reliance on virtual outreach may disproportionately affect engagement with certain community members. Certain audiences (e.g., the elderly, people with disabilities) may have information needs and communication preferences that may not be addressed in a responsive, tailored way during pandemic conditions (OxFam, 2020).

- While previous efforts (e.g., Ott et al., 2018) have indicated that the sharing of vetted online resources can be an important strategy to improve community resilience and disaster preparedness, online or "virtual" outreach also presents barriers to capacity-building engagement during COVID-19 for Extension professionals. A lack of experience with or access to some remote technologies among Extension personnel, non-Extension colleagues, partner stakeholders, and clientele may limit the quality of engagement (Fawcett et al., 2020). Additionally, community members may have limited or intermittent internet access to begin with (Fawcett et al., 2020). 
- Lindsey et al. (2018) have suggested that social networks and "sense of place" connections within a community are fundamental to resilience building. The fostering of social networks to build capacity and resilience within disaster preparedness/response contexts has often involved participatory planning processes that conventionally require direct, face-to-face interaction between community members (Weaver, 2016). During COVID-19 and any future pandemic scenario, these physical assemblies represent a potential health and safety risk and therefore pose a challenge to implementation.

\section{Recommendations for Building Community Resilience during COVID-19 and Future Pandemic \\ Scenarios}

- One of the obvious solutions to address barriers to physical engagement during COVID-19 has been to increase the use of remote technologies (Fawcett et al., 2020). By leveraging the use of videoconferencing technology, webinars, and other forms of virtual engagement, program planners can still promote resilience and capacitybuilding programming while facilitating participatory engagement with community members. Without targeted curricula or programming, however, online engagement itself is not necessarily adequate or effective for building resilience and capacity in communities. Two UF/IFAS resources (Ott et al., 2018; Monaghan et al., 2018) provide useful guidance on promoting community resilience through online toolkits compiled from the Florida Department of Health (FDOH), the Center for Disease Control (CDC), FEMA, and the Extension Disaster Education Network (EDEN).

- Agents should attempt to learn about existing community-led initiatives and the efforts of local organizations actively engaged in community capacity building. These stakeholder engagement efforts may involve the sharing of both "hard" data (e.g., the number of free food box distributions from a local church) and "soft" data (learned experiences from community organizers) and may be a starting point to produce asset mapping and community visioning outputs. Extension professionals can encourage participation and a sense of community virtually by:

- Creating a permanent communication channel or "team" page within platforms such as Microsoft Teams, Discord, or Slack where community members can exchange questions and resources and access postevent webinar recordings if they were not able to attend a live event.
- Utilizing "breakout" room features in videoconferencing platforms such as Zoom or Skype during virtual assemblies/stakeholder meetings. Smaller group engagement may encourage participation from individuals less inclined to contribute in large-body meetings.

- Balancing time for preplanned "seed" questions (designed to stimulate discussion) with time for open discussion to ensure that there is ample opportunity for unaddressed questions to be answered.

- Emphasizing during meetings that each individual is an expert on their own lives, needs, and experiences relative to how COVID-19 has impacted them. Every community member or organizational representative will have developed resilience strategies to adapt to the pandemic that may be transferable and scalable. Highlighting this possibility may strengthen coordination, collaboration, and trust between community members and stakeholder organizations.

- Finally, Extension professionals should seek out more specialized guidance and resources developed by organizations focused on community resilience and capacity building during disaster scenarios. This is particularly important in relation to monitoring and evaluating changes in community capacity and resilience, which may involve complex metrics and constructs (e.g., collective efficacy, perceived preparedness, community engagement). The EDEN resource, "Epidemic Preparedness for Community Organizations," for example, provides targeted guidelines and resources (e.g., recovery assessment templates) designed to facilitate resilient community-scale recovery (EDEN, 2018).

\section{Conclusion}

While specific roles, processes, and degrees of involvement vary by state and county, Extension continues to play an important part in disaster planning and response events (Eighmy et al., 2012). This has remained true during the COVID-19 pandemic. Beyond simply sharing information about the virus, Extension professionals across the country have considered techniques to promote community resilience and capacity building as an effective disaster mitigation and response strategy (Fawcett et al., 2020; University of Wisconsin, 2020). To effectively promote resilience and capacity building during COVID-19 and future pandemic scenarios, Extension must be adaptive and flexible. The recommendations offered here are a starting point for Extension professionals to consider not only for COVID-19, but for future pandemic scenarios. 


\section{References}

Béné, C. (2020). Resilience of local food systems and links to food security-A review of some important concepts in the context of COVID-19 and other shocks. Food Security, 12, 805-822. https://doi.org/10.1007/s12571-020-01076-1

Devereux, S., Béné, C., \& Hoddinott, J. (2020). Conceptualizing COVID-19's impacts on household food security. Food Security, 12(4), 769-772. https://doi.org/10.1007/ s12571-020-01085-0

Eighmy, M. A., Hall, T. E., Sahr, E., Gebeke, D., \& Hvidsten, M. (2012). The Extension service and rural/frontier disaster planning, response, and recovery. Journal of Extension, 50(4), n4. https://joe.org/joe/2012august/a10.php

Extension Disaster Education Network (EDEN) (2018). Epidemic preparedness for community organizations. https://extensiondisaster.net/resource-dashboard/ epidemic-preparedness-for-community-organizations/

Fawcett, J. E., Parajuli, R., Bardon, R., Boby, L., Kays, L., \& Strnad, R. (2020). Tools for quickly adapting during pandemics, disasters, and other unique events. Journal of Extension, 58(2), n2. https://www.joe.org/joe/2020april/tt1. php

Federal Emergency Management Agency (FEMA) (n.d.). COVID-19 disaster declarations. https://www.fema.gov/ disasters/coronavirus/disaster-declarations

Lindsey, A. B., Goldenberg, S., \& Wandersee, C. (2018). Developing and Strengthening Networks to Promote Resilience After Disasters. FCS3346. Gainesville: University of Florida Institute of Food and Agricultural Sciences. https:// edis.ifas.ufl.edu/fy1477

Mitrofanova, Y. (2014). Building community capacity. University of Nebraska-Lincoln. https://lancaster.unl.edu/ community/articles/capacity.shtml

Monaghan, P., Ott, E., \& Fogarty, T. (2018). Measuring Community Resilience Using Online Toolkits. AEC507. Gainesville: University of Florida Institute of Food and Agricultural Sciences. https://edis.ifas.ufl.edu/wc172

Ott, E., Monaghan, P., \& Fogarty, T. (2018). Extension and Community Resilience: Improving Community Disaster Preparedness Using Online Resources. AEC525. Gainesville: University of Florida Institute of Food and Agricultural Sciences. https://edis.ifas.ufl.edu/wc187
OxFam. (2020). Community engagement during COVID-19: A guide for community-facing staff. https://www.oxfamwash. org/response-types/covid-19/OXCTF_Protecting\%20Community $\% 20$ Facing $\% 20$ Staff $\% 20$ and $\% 20$ Volunteers.pdf

Weaver, R. (2016). Capacity building and community resilience: A pilot analysis of education and employment indicators before and after an Extension intervention. Journal of Extension, 54(2), n2. https://joe.org/joe/2016april/a1.php

\section{Appendix: The Road to Recovery Series Overview}

The COVID-19 pandemic created the need for this Road to Recovery series of EDIS publications. Six publications are included, covering topics to assist Extension professionals and State specialists in addressing client needs and evaluating techniques for virtual engagement. Brief summaries of each publication in the series are provided below.

\section{Road to Recovery \# 1: Introduction}

Summarizes the implications of the COVID-19 pandemic on Extension professionals' operations and presents necessary adaptations and key considerations to safely improve delivery and impact. Road to Recovery \#2: Building Physical and Emotional Trust When Engaging with Extension Clientele

Provides information and recommendations to address emotional and physical trust gaps clientele may experience in the face of a pandemic by using intentional, strategic efforts when engaging in the field or via virtual platforms.

\section{Road to Recovery \#3: Facilitating Community Resilience for Effective Pandemic Response}

Considers challenges posed by the pandemic and the importance of community-led initiatives and provides alternative strategies for facilitating building resiliency, capacity, and social capital involving community stakeholders and clients.

\section{Road to Recovery \#4: Evaluating Virtual Techniques to Reach Clientele and Promote Equity}

Offers guidance on how to effectively assess which audiences are being reached through virtual engagement and which audiences may be "falling through the cracks;" includes information on leveraging social media and virtual platform analytics, applying audience segmentation, and using online surveys and polls. 


\section{Road to Recovery \#5: Evaluating Virtual Facilitation to}

Build Trust

Provides information on how educators can evaluate their efforts to facilitate trust through remote learning and virtual engagement, especially important during a pandemic; considers users' concerns about cybersecurity and common anxieties, discomfort, and competency gaps using online platforms.

\section{Road to Recovery \#6: Evaluating Virtual Strategies to Build Community Capacity and Resiliency}

Offers support for agents interested in evaluating their use of virtual strategies to promote participatory engagement and community-capacity building; provides recommendations for agents to better assess whether virtual techniques improve users' perceptions of collective efficacy and community capacity during pandemic scenarios. 